\title{
Estudo da relação entre a imunoexpressão das proteínas caderina-E e DCC com 0 grau de diferenciação celular e 0 estadiamento TNM do adenocarcinoma colorretal
}

\author{
Study of the expression of E-cadherin and DCC proteins with cell differentiation degree and staging in \\ colorectal adenocarcinoma
}

Marcos Vinicius Araújo Denadai'; Sandra Regina M. da Silva'; Angela F.L. Waitzberg²; Ricardo Artigiani33; Sarhan Sydney Saad ${ }^{4}$; Delcio Matos ${ }^{5}$

\begin{abstract}
unitermos
Caderina-E

DCC

Neoplasias do cólon

Cólon

Reto

\section{resumo}

Objetivo: Avaliar a relação de duas proteínas que participam do mecanismo de adesão celular com o grau de diferenciação celular e os estadiamentos TNM (T: tumor, N: linfonodo, M: metástase) I e IV no câncer de cólon e reto. Métodos: Foram estudados cem pacientes (54 homens e 46 mulheres) tratados por adenocarcinoma colorretal, estádios I (44) e IV (56). Os cortes histológicos do tecido tumoral foram examinados por técnica de imuno-histoquímica em relação à imunoexpressão das proteínas caderina-E e delect in colon cancer (DCC), sendo classificados como positivos quando se detectou a imunoexpressão dessas proteínas em 50\% ou mais das células tumorais. Resultados: Para o TNM, imunoexpressão da caderina-E estádio I: positiva em 72,7 \% e negativa em $35,7 \%$; estádio IV: positiva em $64,3 \%$ e negativa em $35,7 \%$. Proteína DCC: $43,2 \%$ positiva e $56,8 \%$ negativa no estádio I, e $50 \%$ positiva e $50 \%$ negativa no estádio IV. Em relação ao grau de diferenciação celular, imunoexpressão da caderina-E - GI: positiva em 70\% e negativa em 30\%; Gll: positiva em 68,4\% e 31,6\% negativa; GIII: 63,6\% positiva e $36,4 \%$ negativa. Imunoexpressão da DCC - Gl: $40 \%$ positiva e $60 \%$ negativa; Gll: $46,8 \%$ positiva e 53,2\% negativa; GIll: $54,5 \%$ positiva e $45,5 \%$ negativa. Não houve diferença significativa entre os grupos. Conclusão: Os resultados dessa pesquisa permitem concluir que não há relação da imunoexpressão das proteínas caderina-E e DCC com o estadiamento TNM (I e IV) e o grau de diferenciação celular no carcinoma colorretal.
\end{abstract}

\section{abstract}

Objective: Evaluate the relationship of two proteins, which take part in the same mechanism of cell adhesion, with the cell differentiation degree and TNM staging I and IV in colorectal cancer. Methods: One-hundred patients (54 men and 46 women), who have received treatment for colorectal cancer, stages I (44) and IV (56), have been studied. Histological cuts of tumor tissue were examined by the immunohistochemical technique as to the expression of E-cadherin and delect in colon cancer (DCC) proteins, being classified as positive whenever it was detected immunoexpression of such proteins in $50 \%$ or more tumor cells. Results: For TNM, E-cadherin immunoexpression for stage I: positive in $72.7 \%$ and negative in $35.7 \%$; stage IV: positive in $64.3 \%$ and negative in $35.7 \%$. For DCC protein: $43.2 \%$ positive and $56.8 \%$ negative in stage I, and $50 \%$ positive and 50\% negative in stage IV. Regarding the cell differentiation degree, the immunoexpression of E-cadherin - GI: positive in 70\% and negative in 30\%; GII: positive in $68.4 \%$ and negative in $31.6 \%$; GIII: positive in $63.6 \%$ and negative in $36.4 \%$. The immunoexpression of DCC - Gl: $40 \%$ positive and $60 \%$ negative; GII: $46.8 \%$ positive and $53.2 \%$ negative; GIII: $54.5 \%$ positive and $45.5 \%$ negative. There was no significant difference among groups. Conclusion: The results of this research make it possible to come to the conclusion that there is no relationship between the immunoexpression of E-cadherin and DCC proteins with TNM staging (I and IV) and cell differentiation degree in colorectal cancer. key words

E-cadherin

DCC

Colon neoplasia

Colon

Rectum

\footnotetext{
1. Médicos do Departamento de Cirurgia Oncológica da Fundação Pio XII - Hospital do Câncer, Barretos-SP.

2. Professora-adjunta; doutora do Departamento de Patologia da Escola Paulista de Medicina da Universidade Federal de São Paulo (EPM/UNIFESP).

3. Médico-assistente; membro do Departamento de Patologia da EPM/UNIFESP.

4. Professor-associado; doutor em Castroenterologia Cirúrgica pela UNIFESP.

5. Professor-associado; live--docente da disciplina de Castroenterologia Cirúrgica da EPM/UNIFESP
} 


\section{Introdução}

O carcinoma colorretal representa um problema de saúde pública mundial. $\mathrm{O}$ número de novos casos de câncer colorretal estimado para o Brasil em 2006 foi de 11.390 em homens e 13.970 em mulheres ${ }^{(13)}$.

Pacientes portadores de carcinoma colorretal em estádios iniciais apresentam bom prognóstico, porém, nos estádios avançados da doença, há uma notável redução da sobrevida (20\% em cinco anos) ${ }^{(26)}$. Entretanto, alguns pacientes com doença localizada morrem por recidiva tumoral mesmo recebendo o tratamento adequado ${ }^{(31)}$.

Diante desses fatos, trabalhos na literatura foram elaborados na tentativa de traçar um perfil prognóstico para o carcinoma colorretal, levando em conta não só as informações do exame anatomopatológico e de estadiamento, mas também o conhecimento das estruturas que participam das funções básicas da célula, como o processo de adesão celular e a capacidade de angiogênese, envolvidos também na carcinogênese $\mathrm{e}^{(10,20,28)}$.

Foi observado que a deleção alélica do braço longo do cromossomo $18 q$ era uma alteração genética comum no carcinoma colorretal ${ }^{(24)}$. Posteriormente, constatou-se que o gene localizado nessa região deletada era supressor de tumor, o qual foi chamado de deleted in colon cancer (DCC). Sua função está relacionada com a codificação de uma proteína transmembrana com o segmento extracelular contendo domínios semelhantes à imunoglobulina $a^{(4,15)}$. Deduziu-se, então, que a proteína DCC desempenha uma função essencial na modulação da adesão célula-célula, participando do processo de crescimento e diferenciação celular da mucosa colônica normal(3).

Fearon et al., em 1990, concluíram que o gene DCC estava presente no tecido normal, incluindo a mucosa colônica, porém sua imunoexpressão estava reduzida ou ausente na maioria dos carcinomas colorretais avaliados nesse estudo(4).

A redução da imunoexpressão do gene $D C C$ foi observada também em outros tumores malignos, como no adenocarcinoma prostático(5).

A perda do alelo do cromossomo $18 q$ foi evidenciada em $70 \%$ dos casos de carcinoma colorretal, sendo $20 \%$ nos tumores estádio I e apenas $2 \%$ nos adenomas esporádicos, sugerindo também a participação desse gene nos processos finais da carcinogênese ${ }^{(27)}$.

Kubo et al. revelaram que indivíduos jovens com câncer colorretal e pacientes com tumores bem diferenciados, apresentando alterações no gene DCC (perda do heterozi- goto), tinham maior incidência de linfonodos acometidos pela doença e metástases à distância(20).

A proteína caderina-E, outro foco deste estudo, também desempenha importante papel no mecanismo de adesão celular. Atua mediando as interações célula-célula e célulamatriz extracelular, mantendo, dessa forma, a integridade do tecido epitelial. Pertencente a uma família de glicoproteínas transmembrana, é cálcio-dependente e está presente sobre a superfície das células ${ }^{(31)}$.

Evidências indicam que a perda da função da caderina- $E$ está relacionada com o processo de diferenciação e metástases no carcinoma de mama e de esôfago ${ }^{(22,26)}$.

A perda da imunoexpressão da caderina-E e das cateninas foi associada com mecanismo de invasão tumoral e metástases à distância, sugerindo um potencial fator prognóstico no carcinoma colorretal em trabalhos de Ghadimi et al. ${ }^{(7)}$ e Gofuku et al. ${ }^{(8)}$.

Por outro lado, Kitadai et al.(19) não evidenciaram relação estatística da perda da imunoexpressão da caderina-E com metástases hepáticas no carcinoma colorretal, e Leme et al. ${ }^{(21)}$ não relacionaram a imunoexpressão da proteína caderina-E com o estadiamento TNM (T: tumor, N: linfonodo, M: metástase) e o prognóstico.

A diversidade de resultados - até controversos - em literatura específica motivou esta investigação no sentido de procurar estabelecer a relação entre a imunoexpressão das proteínas caderina-E e DCC, consideradas vias distintas participantes do processo de adesão celular, com variáveis histopatológicas nos carcinomas colorretais localizado (estádio I) e avançado (estádio IV).

\section{Objetivo da pesquisa}

Verificar a associação entre a imunoexpressão das proteínas caderina-E e DCC e o grau de diferenciação celular e o estadiamento TNM (estádios I e IV) do adenocarcinoma colorretal.

\section{Material e métodos}

Este estudo de natureza retrospectiva foi desenvolvido nos departamentos de Cirurgia Oncológica e Anatomia Patológica do Hospital do Câncer de Barretos - Fundação Pio XII. As amostras biológicas foram coletadas do arquivo do Laboratório de Patologia da Fundação Pio XII e os dados clínicos, coletados no Serviço de Arquivo Médico e Estatística (SAME). 
O protocolo de pesquisa foi enviado e aprovado pelo comitê de ética em pesquisa da Fundação Pio XII de Barretos e pela comissão de ética em pesquisa da Universidade Federal de São Paulo (UNIFESP), sem restrições, sob o número 0333/04, em 18-6-2004.

A amostra foi constituída de cem pacientes portadores de carcinoma colorretal tratados no Hospital de Câncer de Barretos - Fundação Pio XII, no período de 1993 a 2004, divididos em dois grupos de estadiamento segundo as normas do TNM ${ }^{(1)}: 44$ pacientes estádio I (pT1 ou pT2 N0 M0) e 56 pacientes estádio IV (qualquer T, qualquer N, M1).

\section{Critérios de inclusão}

Foram incluídos pacientes admitidos no hospital para tratamento pertencentes apenas aos estádios I e IV, classificados de acordo com o sistema TNM, que possuíam, arquivados no departamento de Patologia, prontuário médico e blocos de parafina representando o tumor primário ou a lesão metastática.

Para definir o diagnóstico e o estadiamento foram utilizados: biópsia do tumor colorretal, exames de imagem (raios X [RX], tomografia computadorizada [TC] e ultrasonografia [US]), biópsia da lesão metastática, achado intraoperatório e laudo do exame anatomopatológico. No grupo considerado estádio I, seis pacientes dos casos selecionados receberam tratamento pré-operatório com radioterapia e quimioterapia e dois apenas radioterapia neo-adjuvante, num total de oito (18\%) pacientes em 44 casos.

\section{Critérios de exclusão}

Foram considerados critérios de exclusão: indisponibilidade de dados clínicos e/ou anatomopatológicos, estadiamentos TNM II e III, pacientes portadores de polipose familiar, outros tipos histológicos e tumores metacrônicos.

\section{Características da amostra}

Em relação ao sexo dos pacientes, ficou assim distribuído: 18 (41\%) do feminino e 26 (59\%) do masculino no grupo estádio l; e 28 (50\%) do feminino e 28 (50\%) do masculino no estádio IV. O tipo histológico predominante foi o adenocarcinoma clássico tubular.

Quanto ao grau de diferenciação celular para o estádio I: nove tumores (20,4\%) grau l; 33 (75\%) grau Il e dois (4,5\%) grau III. Nos pacientes em estádio IV, um $(1,8 \%)$ tumor foi classificado como grau l; $46(82,1 \%)$ eram grau II e nove (16\%) grau III.

Uma síntese dos resultados das variáveis está disposta na Tabela 1.

\section{Técnica imuno-histoquímica e avaliação dos resultados}

Para avaliação da imunoexpressão das proteínas DCC e caderina-E pelo método de imuno-histoquímica foram usados anticorpos primários monoclonais: a) DCC Novocastra NCL-DCC, clone D M 51, diluição de $1 / 200 ; b$ ) E-cadherin Novocastra NCL E-cad, clone 36 B 5, diluição de $1 / 100$.

Os blocos de parafina foram recortados em micrótomo rotativo, obtendo-se cortes histológicos de 2 a 3 micras de espessura e depositados em lâminas previamente tratadas com silano (3-aminopropyl-triethoxilane, SIGMA A-3648, USA) com a reação utilizando o complexo avidina-biotina-peroxidase $(A B C) /$ estreptavidina-biotina-peroxidase (StreptABC), Kit Universal Super ABC - Erviegal.

A avaliação das proteínas foi realizada por leitura das lâminas histológicas em microscópio ótico (40x lente objetiva) por três médicos patologistas que desconheciam o estadiamento do material.
Tabela 1 segundo os estádios I e IV

\begin{tabular}{lccc}
\hline Estadiamento & & TNM I & TNM IV \\
Sexo & Masculino & $n=44$ & $n=56$ \\
\multirow{2}{*}{ Média das idades (anos) } & Feminino & $18(41 \%)$ & $28(50 \%)$ \\
& & 61 & $28(50 \%)$ \\
Grau de diferenciação celular & grau I & $9(20,4 \%)$ & 55 \\
& grau II & $33(75 \%)$ & $1(1,8 \%)$ \\
& grau III & $2(4,5 \%)$ & $46(82,1 \%)$ \\
\hline
\end{tabular}

TNM: T: tumor, N: linfonodo, M: metástase. 
O critério adotado foi o seguinte: foram considerados positivos os achados quando se detectou a presença da proteína caderina-E na membrana celular em $50 \%$ ou mais das células tumorais; e negativos quando se verificou ausência da proteína, localização no citoplasma, menos de $50 \%$ de células com imunoexpressão caderina-E.

Para a proteína DCC foi adotado o mesmo método: $50 \%$ ou mais de imunoexpressão da proteína foi considerado positivo e menor que $50 \%$, negativo. Os resultados foram obtidos em consenso entre os patologistas, aplicando-se o método quantitativo.

As Figuras 1 a 4 representam a imunoexpressão dessas proteínas pelo método imuno-histoquímico.

Os resultados foram submetidos a tratamento estatístico com a finalidade de determinar se existe correlação entre a imunoexpressão das proteínas caderina-E e DCC com o estadiamento e com o grau de diferenciação tumoral no carcinoma colorretal.

O teste de qui-quadrado de Pearson foi empregado para a comparação dos dados coletados com os resultados

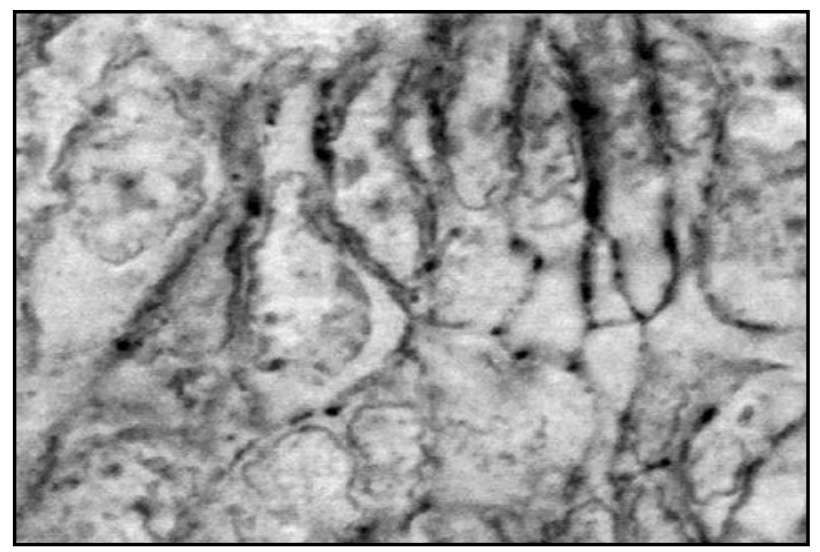

Figura 1 - Fotomicrografia do carcinoma colorretal com imunoexpressão positiva na membrana celular da proteína caderina-E (400x)

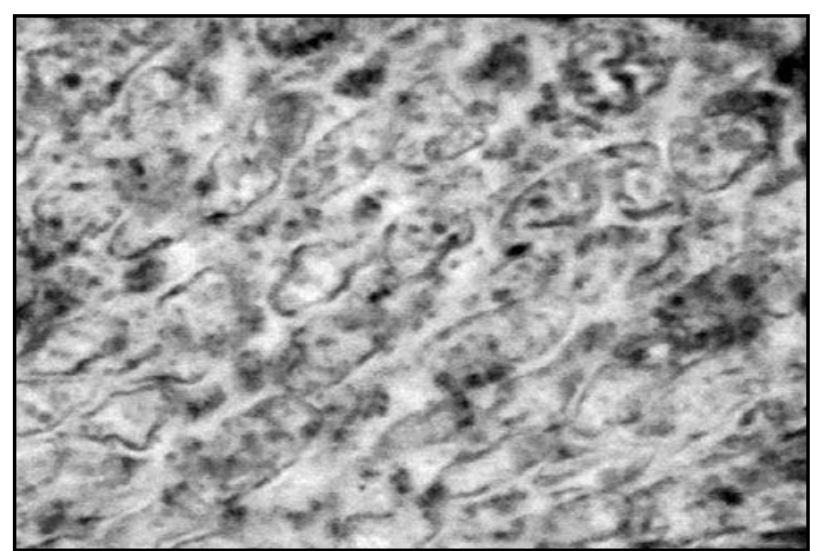

Figura 3 - Fotomicrografia do carcinoma colorretal com imunoexpressão da proteína DCC classificada como positiva (400x) obtidos da imunoexpressão das proteínas DCC e caderina-E, adotando como nível de significância $p \leq 0,05$.

\section{Resultados}

\section{Imunoexpressão das proteínas caderina-E e DCC no estadiamento TNM}

Em relação à caderina-E para o estadiamento I: imunoexpressão positiva em 32/44 (72,7\%) pacientes e imunoexpressão negativa em 12/44 (27,2\%). Para o estádio IV: imunoexpressão positiva em 36/56 (64,2\%) pacientes e negativa em 20/56 (35,7\%). Não houve diferença significativa entre os grupos $(p=0,37)$.

Em relação à proteína DCC, verificaram-se 19/44 $(43,1 \%)$ pacientes com imunoexpressão positiva e $25 / 44$ $(56,8 \%)$ com negativa para o estádio I. Para o estádio IV: 28/56 (50\%) pacientes com imunoexpressão positiva e 28/56 (50\%) com negativa, não havendo diferença significativa $(p=0,5)$.

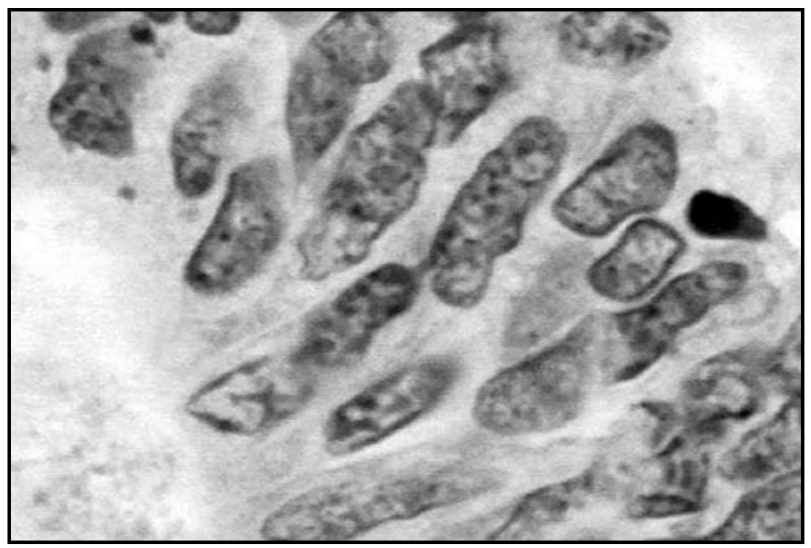

Figura 2 - Fotomicrografia do carcinoma colorretal com imunoexpressão negativa da proteína caderina-E (400x)

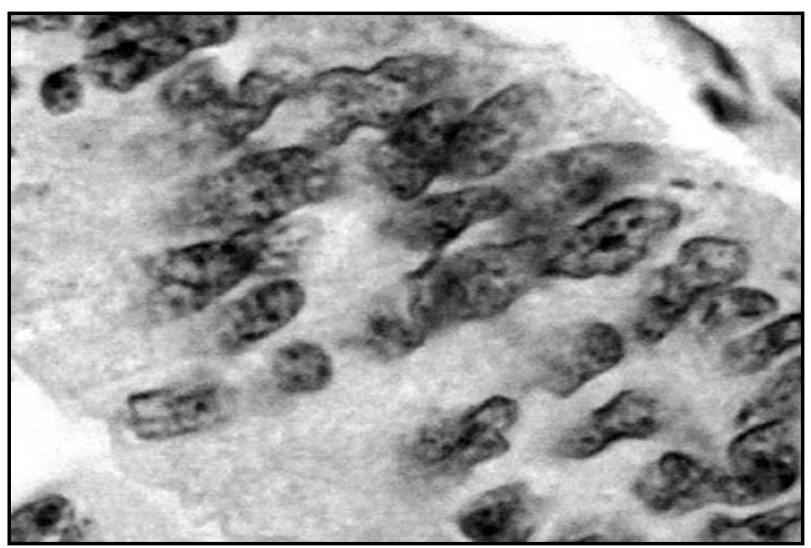

Figura 4 - Fotomicrografia do carcinoma colorretal com imunoexpressão da proteína DCC classificada como negativa (400x) 


\section{Imunoexpressão das proteínas caderina-E e DCC e grau de diferenciação celular}

Para os tumores grau I, imunoexpressão da caderina-E positiva em $7 / 10$ (70\%) casos e negativa em 3/10 (30\%). Nos de grau II, os achados positivos totalizaram 54/79 $(68,3 \%)$ casos e $25 / 79(31,6 \%)$ negativos; e nos tumores grau III, 7/11 (63,6\%) casos com imunoexpressão positiva e 4/11 (36,3 \%) com negativa. Não houve diferença significativa observada entre os grupos $(p=0,94)$.

Em relação à proteína $\mathrm{DCC}$, os dados encontrados foram: imunoexpressão positiva em 4/10 (40\%) casos e negativa em 6/10 (60\%) casos para os tumores grau I; imunoexpressão positiva em $37 / 79$ (46,8\%) casos e negativa em $42 / 79(53,1 \%)$ casos de tumores grau II; e para os tumores grau III, imunoexpressão positiva em $6 / 11$ (54,5\%) casos e negativa em 5/11 $(45,4 \%)$ casos de carcinoma colorretal. Não houve diferença significativa $(p=0,8)$.

\section{Imunoexpressão das proteínas caderina-E e DCC no total de casos estudados}

Analisando os resultados das variáveis (DCC e caderina-E) no total de pacientes estudados $(n=100)$, verificaram-se $68 \%$ de imunoexpressão positiva para a proteína caderina-E e 32\% de imunoexpressão negativa. Houve diferença significativa $(p<0,001)$ entre esses dados. Para a proteína DCC, os resultados foram os seguintes: $47 \%$ de imunoexpressão positiva e $53 \%$ de negativa. Não houve diferença significativa $(p=0,56)$ nessa assimetria de dados.

Os resultados das variáveis estudadas nos pacientes selecionados para esse trabalho estão dispostos na Tabela 2.

\section{Discussão}

A identificação da caderina-E pelo método imuno-histoquímico foi realizada pela detecção da coloração marrom localizada na membrana celular.

Na literatura há variação dos critérios que determinam a positividade da imunoexpressão da caderina-E. Alguns consideram positiva a imunoexpressão da caderina-E quando $90 \%$ das células tumorais encontram-se coradas pelo método, enquanto que, para outros, o critério de positividade situa-se entre $25 \%$ e $50 \%$ das células cora$\operatorname{das}^{(12,17)}$

No total dos cem pacientes estudados, o resultado encontrado foi de $32 \%$ de imunoexpressão negativa para a proteína caderina-E e $68 \%$ de imunoexpressão normal, estando esse valor dentro dos parâmetros detectados pelos trabalhos da literatura ${ }^{(6,8)}$ e com diferença estatística significativa $(p<0,001)$.

Do mesmo modo como ocorre com a proteína caderina-E, não existe um consenso na literatura sobre o critério adotado para classificar a imunoexpressão da proteína DCC como normal (positiva) ou alterada (negativa), encontrando-se resultados discordantes.

Wu et al. ${ }^{(32)}$ consideraram o ponto de corte para a imunoexpressão positiva em $50 \%$ ou mais de células expressando a proteína DCC, sendo também adotado esse mesmo parâmetro de classificação neste estudo.

Neste estudo não se identificou correlação entre a imunoexpressão da proteína caderina-E e o estadiamento TNM, ou seja, a perda da imunoexpressão não se relacionou com o estádio mais avançado da doença.

\section{Tabela 2 estadiamento TNM e 0 grau de diferenciação celular}

\begin{tabular}{lccccc}
\hline Proteína & \multicolumn{2}{c}{ Estadiamento } & \multicolumn{3}{c}{ Grau de diferenciação } \\
\cline { 2 - 6 } Caderina-E positiva & TNM I & TNM IV & Grau I & Grau II & Grau III \\
& $32 / 44$ & $36 / 56$ & $7 / 10$ & $54 / 79$ & $7 / 11$ \\
Caderina-E negativa & $72,7 \%$ & $64,2 \%$ & $70 \%$ & $68,3 \%$ & $63,6 \%$ \\
& $12 / 44$ & $20 / 56$ & $3 / 10$ & $25 / 79$ & $4 / 11$ \\
DCC positiva & $27,2 \%$ & $35,7 \%$ & $30 \%$ & $31,6 \%$ & $36,3 \%$ \\
& $19 / 44$ & $28 / 56$ & $4 / 10$ & $37 / 79$ & $6 / 11$ \\
DCC negativa & $43,1 \%$ & $50 \%$ & $40 \%$ & $46,8 \%$ & $54,5 \%$ \\
& $25 / 44$ & $28 / 56$ & $6 / 10$ & $42 / 79$ & $5 / 11$ \\
& $56,8 \%$ & $50 \%$ & $60 \%$ & $53,1 \%$ & $45,4 \%$ \\
\hline
\end{tabular}

DCC: delected in colon cancer; TNM: T: tumor, N: linfonodo, M: metástase. 
Outros trabalhos também revelam resultados semeIhantes, não encontrando relação da imunoexpressão da caderina-E com o estadiamento, como apresentado por Karatzas et al. ${ }^{(17)}$; Hugh et al. ${ }^{(10)}$.

Porém, na literatura existem estudos que identificam correlação entre a imunoexpressão da caderina-E e o estadiamento TNM, como os de Mohri et al. ${ }^{(23)}$, Ikeguchi et al. ${ }^{(11)} \mathrm{e}$ Kaihara et al. (16), que relacionaram a perda da imunoexpressão dessa proteína com os tumores em estádios avançados.

Existem diferenças metodológicas entre os trabalhos citados tanto na leitura dos resultados obtidos pela imunohistoquímica, quanto na comparação com os estadiamentos do sistema TNM, não havendo, portanto, uma padronização adotada. Esse fato pode interferir na análise quando se comparam o resultados da literatura.

Os trabalhos de Leme et al. ${ }^{(21)}$ e Jesus et al. ${ }^{(14)}$ são equivalentes quanto à metodologia em relação ao TNM, comparando todos os estádios da doença com a imunoexpressão da proteína caderina-E e não encontrando relação estatística, o que reforça a hipótese de que essa proteína não participa do processo de progressão tumoral.

No presente estudo também não se evidenciou correlação entre a imunoexpressão da proteína DCC e o estadiamento TNM para o carcinoma colorretal.

Shibata et al.(31), estudando 132 casos de carcinoma colorretal nos estádio II e III, não encontraram relação entre a imunoexpressão da proteína DCC e o estadiamento.

Para Aschele et al. ${ }^{(2)}$, o estudo de 42 pacientes portadores de carcinoma colorretal com doença metastática (M1) revelou $45 \%$ de tumores com imunoexpressão positiva e $55 \%$ com negativa para DCC (sem relação estatística).

Wu et al. (32), utilizando o método de imuno-histoquímica para detecção da imunoexpressão da DCC em pacientes estádios II e III, também não encontraram relação estatística entre os dois grupos.

Além da falta de padronização para realizar a análise do material e a existência de diferentes grupos do estadiamento TNM comparados com a imunoexpressão da proteína DCC, encontramos resultados semelhantes na literatura, reforçando a hipótese de que essa proteína não participa da progressão do adenocarcinoma colorretal.
Em relação ao grau de diferenciação celular, neste estudo houve um predomínio de tumores grau II (moderadamente diferenciados): $75 \%$ de tumores estádio I e $83,9 \%$ de estádio IV, fato também observado em outros trabalhos da literatura ${ }^{(12)}$.

No presente estudo não foi encontrada correlação entre a imunoexpressão da caderina-E e o grau de diferenciação celular. Esse fato pode estar relacionado com o grande número de tumores grau II encontrado e com o reduzido número de tumores grau III nessa amostra, o que pode acarretar alterações na análise estatística.

Guzinska-Ustymowicz et al.(9), estudando a imunoexpressão da caderina-E em 34 pacientes com carcinoma colorretal, classificados pelo exame anatomopatológico como pT1, por imuno-histoquímica, evidenciaram forte relação entre a perda da imunoexpressão e o grau histológico.

Outros estudos, como os citados a seguir, não mostraram relação da caderina-E com a diferenciação celular: llyas et al. ${ }^{(12)}$, analisando 68 casos de tumor colorretal, não encontraram relação significativa com o grau de diferenciação; Kaihara et al.(16) e Jesus et al.(14), analisando 117 pacientes, não identificaram correlação entre a proteína caderina-E e o grau de diferenciação celular.

Relacionando a imunoexpressão da proteína DCC com o grau de diferenciação celular dos tumores neste estudo, não se identificou diferença significativa entre os resultados obtidos. Esse dado também está presente em outros trabalhos na literatura. Shibata et al.(31), analisando 132 pacientes, não encontraram relação entre a DCC e o grau de diferenciação celular. Fato semelhante foi demonstrado por Wu et al.(32), que, estudando pacientes estádios II e III com carcinoma colorretal, encontraram mais de $90 \%$ de tumores grau I em 168 casos estudados.

\section{Conclusão}

Os resultados desta pesquisa permitem concluir que não há relação entre as expressões das proteínas caderinaE e DCC, o estadiamento TNM e o grau de diferenciação celular no carcinoma colorretal.

\section{Referências}

1. AMERICAN JOINT COMMITTEE ON CANCER. Colon and rectum. Philadelphia: Lippincott-Raven; 2002. 113p.
2. ASCHELE, C. et al. Deleted in colon cancer protein expression in colorectal cancer metastases: a major predictor of 
survival in patients with unresectable metastatic disease receiving palliative fluorouracil-based chemotherapy. $J$ Clin Oncol, v. 22, p. 3758-65, 2004.

3. CHO, K. R.; FEARON, E. R. DCC: linking tumour suppressor genes and altered cell surface interactions in cancer? Eur J Cancer, v. 31A, p. 1055-60, 1995.

4. FEARON, E. R. et al. Identification of a chromosome $18 \mathrm{q}$ gene that is altered in colorectal cancers. Science, v. 247, p. 49-56, 1990.

5. GAO, X. et al. Frequent loss of expression and loss of heterozygosity of the putative tumor suppressor gene DCC in prostatic carcinomas. Cancer Res, v. 53, p. 382-7, 1993

6. GARINIS, G. A. et al. Hypermethylation-associated transcriptional silencing of E-cadherin in primary sporadic colorectal carcinomas. J Pathol, v. 198, p. 442-9, 2002.

7. GHADIMI, B. M. et al. Immunohistological analysis of Ecadherin, $\alpha, \beta$ catenin expression in colorectal cancer: implications for cell adhesion and signaling. Eur J Cancer, v. 35, p. 60-5, 1999.

8. GOFUKU, J. et al. Expression of E-cadherin and alfa-catenin in patients whith colorectal carcinoma. AmJ Clin Pathol, v. 111, p. 29-37, 1999.

9. GUZINSKA-USTYMOWICZ, K.; CHETNIK, A.; KEMONA, A. Effects of changes at the site of E-cadherin expression as an indicator of colon cancer aggressiveness. Rocz Akad Med Bialymst, v. 49, p. 70-2, 2004.

10. HUGH, T. J. et al. Bet-catenin expression in primary and metastatic colorectal carcinoma. Int J Cancer, v. 82, p. 504-11, 1999.

11. IKEGUCHI, M. et al. Reduced E-cadherin expression and enlargement of cancer nuclei strongly correlate with hematogenic metastasis in colorectal adenocarcinoma. Scand J Gastroenterol, v. 35, p. 839-46, 2000.

12. ILYAS, M. et al. Allele loss, replication errors and loss of expression of E-cadherin in colorectal cancers. Gut, v. 40, p. 654-9, 1997.

13. INSTITUTO NACIONAL DO CÂNCER. Estimativas de câncer no Brasil 2006. Rio de Janeiro, 2006. Monografia (on-line) - INCa. Disponível em: http://www.inca.gov.br/ estimativa/2006. Acesso em: 20 fev. 2006.

14. JESUS, E. C. et al. Assessment of staging, prognosis and mortality of colorectal cancer by tumor markers: receptor erbB-2 and cadherins. Acta Cir Bras, v. 20, n. 6, p. 422-7, 2005.

15. JOHNSON, J. P. Cell-cell adhesion molecules of the immunoglobulin supergene family and their role in malignant transformation and progression to metastatic disease. Cancer Metastasis Rev, v. 10, n. 1, p. 11-22, 1991.

16. KAIHARA, T. et al. Dedifferentiation and decreased expression of adhesion molecules, E-cadherin and
ZO-1, in colorectal cancer are closely related to liver metastasis. J Exp Clin Cancer Res, v. 22, n. 1, p. 117-23, 2003

17. KARATZAS, G. et al. E-cadherin expression correlates white tumor differentiation in colorectal cancer. Hepatogastroenterology, v. 46, p. 232-5, 1999.

18. KITADAI, Y. et al. Multiparametric in situ mRNA hybridization analysis to predict disease recurrence in patients with colon carcinoma. Am J Pathol, v. 149, p. 1541-51, 1996.

19. KUBO, H.; MIHI, C.; KUSUNOKI, M. Evaluation of genetic mutations of tumor suppresser genes in colorectal cancer patients. Hepatogastroenterology, v. 51, n. 55, p. 114-7, 2004

20. LEME, M. B. P. et al. A relação da caderina-E com o prognóstico do adenocarcinoma colorretal. Rev Col Bras Cir, v. 32, n. 4, 2005.

21. MIYATA, M. et al. Relationship between E-cadherin expression and lymph node metastasis in human esophageal cancer. Int J Oncol, v. 4, p. 61-5, 1994.

22. MOHRI, Y. Prognostic significance of E-cadherin expression in human colorectal cancer tissue. Surg Today, v. 27, p. 606-12, 1997.

23. MULERIS, M. et al. Consistent deficiencies of chromosome 18 and of the short arm of chromosome 17 in eleven cases of human large bowel cancer: a possible recessive determinism. Ann Genet (Paris), v. 28, p. 206-13,1985.

24. NEWLAND, R. C. et al. Survival after curative resection of lymph node negative colorectal carcinoma. A prospective study of 910 patients. Cancer, v. 76, p. 564-71, 1995.

25. OKA, H. et al. Expression of E-cadherin cell adhesion molecules in human breast cancer tissues and relationship to metastasis. Cancer Res, v. 53, p. 1696-701, 1993.

26. RASHID, A. et al. Genetic epidemiology of mutated K-ras proto-oncogene, altered suppressor genes and microsatellite instability in colorectal adenomas. Gut, v. 44, p. 826-33, 1999.

27. ROSSI, B. M. et al. Câncer de cólon, reto e ânus. São Paulo: Lemar e Tecmedd; 2004.

28. SAITO, M. et al. Expression of DCC protein in colorectal tumors and its relationship to tumor progression and metastasis. Oncology, v. 56, p. 134-41, 1999.

29. SHIBATA, D. et al. The DCC protein and prognosis in colorectal cancer. N Engl J Med, v. 335, p. 1727-32, 1996.

30. TAKEICHI, M. The cadherins: cell-cell adhesion molecules controlling animal morphogenesis. Development, v. 102, p. 639-55, 1988.

31. WU, J. T., et al. Prognostic significance of DCC and p27kip1 in colorectal cancer. Appl Immunohistochem Mol Morphol, v. 13, p. 45-54, 2005

\begin{tabular}{l|l} 
& Endereço para correspondência \\
\hline & Marcos Vinicius Araújo Denadai \\
& Fundação Pio XII - Hospital de Câncer de Barretos \\
& Rua Antenor Duarte Villela, 1.331 - Paulo Prata \\
CEP 14784-400 - Barretos-SP \\
Tel.: (17) 3321-6600 \\
e-mail: mfdenadai@uol.com.br
\end{tabular}

